\title{
Gendering Excellence in Technological Research: A Comparative European Perspective
}

\author{
Liisa Husu', Paula Koskinen²
}

\begin{abstract}
Gender patterns in technological and engineering research careers were explored in the EU funded 13-country study PROMETEA in 2005-2007, including old and new EU member states, and Serbia, the Russian Federation and Chile. Drawing from this study, the article analyses the gendering of key arenas of excellence in technological and engineering research from a comparative international perspective, with a focus on research funding, publishing, scientific prizes and awards, and patents. A central challenge for gender-sensitive science and research policy is how to combine the promotion of scientific excellence with the promotion of gender equality. Exploring the gendering of excellence in technology and engineering research is of special interest because of the strong position this field enjoys in national, European and international research policy and in national research policies, and also because it continues to be the most male-dominated research field. Furthermore, the article discusses methodological challenges of this type of comparative research.
\end{abstract}

Keywords: technological research; engineering; excellence; gender; gate-keeping; research funding; publishing; prizes; comparative research; European Union.

\footnotetext{
' Department of Management and Organization, Hanken School of Economics, Finland, and School of Humanities, Education and Social Sciences, Örebro University, Sweden, P.O.Box 479, 00 I0I HELSINKI, Finland. Phone: +358 (0)40 352I 276. Email: liisa.husu@hanken.fi ${ }^{2}$ Business Innovation Technology Research Centre, Aalto University School of Science and Technology, P.O. Box I5500, FI-00076 Aalto, Finland. Phone: +358 9 4700 I. Email: paula.koskinen@tkk.fi
} 


\section{Introduction}

Technology and engineering as professional spheres are commonly connected with masculinity, and research has demonstrated how the very image of engineering, engineering culture and labour force continue to be heavily gendered (see, for example, Carter \& Kirkup 1990; Mcllwee and Robinson 1992; Mellström 1995; Faulkner 2000). Moreover, just as the stereotypical image of an engineer is male, so is the dominant image of a scientist (for example, Schiebinger 1999; Sjöberg 2002). Technology and engineering also continue to be the most maledominated research fields in Europe and internationally. Women still constitute a minority of researchers in Europe, but this is even more so in technological research and in the business-enterprise sector. In the higher education sector, engineering and technology is the field with the lowest proportion of women researchers in the EU-27. In the professoriate women are a clear minority in Europe and globally (see, for example, Danowitz Sagaria, 2007 and EC, 2009a), but they are especially few among professors of technology, and among leading researchers in industrial and governmental technological research. In 2007 , less than $7.2 \%$ of full professors and their equivalent in engineering and technology were women in the EU-27 (EC, 2005a; EC, 2009a).

A large proportion of technological and engineering research is conducted in the business enterprise sector, which also is the largest research sector in many researchintensive European countries, such as Germany, Finland and Sweden. This sector currently employs the lowest proportions of women researchers of all research sectors in Europe. Only $19 \%$ of researchers in the business enterprise sector in the EU-27 were women in 2006, whereas the proportion of women was more than a third in both higher education and governmental research (EC, 2009a).

In the attempt to strengthen the European research effort, promoting scientific excellence is currently seen as a pivotal issue within the European Commission and other formal bodies of the EU. Excellence and innovation are seen as "the key to European industrial competitiveness", as stated in the European Commission Communication 353 (2004) envisioning the future of European research policy. This includes the creation of "centres of excellence" for research and higher education at European level, and a similar development can also be observed at regional and at national level (see, for example, DFG German Research Foundation, 2008).

A key concern for gender-sensitive science and research policy is how to combine the promotion of scientific excellence with the promotion of gender equality. The landmark European Commission report on women and science, the ETAN report (2000) addressed the issue by its very title: "Promoting excellence through mainstreaming gender equality". The European Commission-initiated international workshop and publication "Gender and Excellence in the Making" (2004) explored the issue of gender bias in measuring scientific excellence, based on research conducted in Europe and USA. One main conclusion was that scientific excellence is not a "universal fact", but rather a social construction, and as such, is open to many kinds of biases, including gender bias. ETAN report and the "Gender and Excellence in the Making" report recommended that further research be conducted in several areas related to scientific excellence, such as differences between scientific disciplines, epistemic cultures, national and regional contexts. Thus far, this kind of research has been scarce. Exploring gendering of excellence in technology and engineering research is of special interest because of the strong position this field enjoys in European and national research policies, and also because it continues to be the most male-dominated research field in Europe.

It is within this broad context that research on the gendering of excellence in technology and engineering research was conducted by PROMETEA ${ }^{3}$, an EU

\footnotetext{
${ }^{3}$ We would like to thank our PROMETEA project partners in the participating countries for the great input they provided. The empirical data for the project, used in this paper is collected by the national teams, in Austria: Birgit Hofstätter, Anita Thaler and Christine Waechter, in Chile: Dámaris Fernández Donoso, Claudia Paz and Sonia Yáñez, in France: André Béraud, AnneSophie Godfroy-Genin, Cloé Pinault, Yvonne Pourrat and Jean Soubrier, in Germany: Jennifer Dahmen, Gaby Hoeborn and Felizitas Sagebiel, in Greece: Nikitas Nikitakos and Maria Lambrou, in Lithuania: Ala Kovieriene, Diana Saparniene and Virginija Sidlauskiene, in Russia: Elena Myasina and Vera Uvarova, in Serbia: Jovan Dudukovic, Jelena Jovanovic and Sanja Vranes, in Slovakia: Oto Hudec and Natasa Urbancikova, in Spain: Carme Alemany, in Sweden: Helen Peterson and Minna Salminen-Karlson, in UK: Wendy Faulkner, Lisa Lee and James Stewart, at Schlumberger : Pierre Bismuth. The data in Finland were collected by Liisa Husu and Paula Koskinen.
}

ISSN: 07I 8-2724. (http://www.jotmi.org)

Journal of Technology Management \& Innovation (C) Universidad Alberto Hurtado, Facultad de Economía y Negocios 
Framework Programme 6 funded research project on empowering women in technological research. The project explored and compared gender patterns in technological and engineering research in twelve European countries along with Chile. Overall, the PROMETEA explored four key topics: (I) women's careers in technological and engineering research, (2) gender in organisational cultures in this research field, (3) good practices in promoting women's careers in the field and (4) gender dynamics and patterns by which scientific excellence is constructed in technological and engineering research. This article focuses on the last of these topics (more generally on results of PROMETEA, see Godfroy-Genin 2010) and also highlights and discusses methodological challenges of this kind of comparative research. Key arenas of scientific excellence internationally and nationally were explored in order to increase understanding of the gendering of excellence in technological and engineering research in different contextual settings.

\section{The Country Contexts: Variation in Research Systems and Gender Systems}

The thirteen countries studied in PROMETEA include both old and new EU member states: Austria, Finland, France, Germany, Greece, Lithuania, the Slovak Republic, Spain, Sweden, and UK, as well as two European countries outside the European Union: the Russian Federation and Serbia, and one country outside of Europe: Chile.

The overall research landscape in terms of research intensity and focus, and the context of technological and engineering research varies in many ways in the thirteen participating countries. Countries range from highly research-intensive to medium and low research intensive, and from those with extensive to medium and low volume in business research sector.

Firstly, a large variation across the PROMETEA countries can be observed in the overall research intensity (measured by the share of the R\&D of the GDP). In Finland and Sweden research intensity is highest in the EU; Austria, France and Germany are placed above the EU average here, and UK slightly below the EU average, whereas research intensity in Greece, Lithuania, Slovakia and Spain remains clearly below the EU average. Secondly, Sweden and Finland topped the EU statistics when it comes to the share of business sector expenditure on the R\&D of the total GDP; Austria, Germany, France and UK being also above the EU-25 average, whereas Greece, Lithuania, Slovakia and Spain were clearly below the EU average in 2003. Thirdly, in terms of the number of researchers (FTE) per 1000 labour force, Finland and Sweden were at the top of the EU-25 rankings in 2003, while Austria, France, Germany, and UK all had figures higher than the EU-25 average, and Greece, Lithuania, Slovakia and Spain figures below the EU-25 average (EC, 2005a).

The overall gender contexts of the participating countries also show a large variation. In the most recent Global Gender Gap comparison, by the World Economic Forum (WEF, 2009), Finland and Sweden were among the global top five countries with lowest gender gap in society, and the only PROMETEA countries within the global top ten. Furthermore, Germany, UK, Spain and France ranked among the global top twenty, whereas the rest of the PROMETEA countries: Austria, Chile, Lithuania, Slovakia and Russia were placed clearly lower, and Greece as the country with largest gender gap among the PROMETEA countries (global 88th), Serbia not being included in the 2009 WEF rankings. European countries in general form a majority, 13 among the top twenty countries with lowest gender gap. It is noteworthy that the indicator does not compare gender equality policies as such but explores how well countries have succeeded in diminishing the gender gap in key societal areas. ${ }^{4}$

When it comes to participation of women in engineering and technological research (see Table I), women's share of the Ph.D.s varies from $14 \%$ in Germany to $40 \%$ in Lithuania. Women's share of professors in engineering and technology is consistently low with no country exceeding $10 \%$, with the proportion of women among all full professors showing much larger variation, from $11 \%$ in Greece to $28.4 \%$ in Serbia. The share of women researchers in the business enterprise sector (also comprising other research fields than technological research) varies from 12\% in Germany to $28 \%$ in Greece and Spain. It is notable that the highest shares of women among engineering Ph.D.s are found in countries with low research intensity in the business enterprise sector

\footnotetext{
${ }^{4}$ The Global Gender Gap index compiled by the World Economic Forum in 2009 measured gender equality in 136 countries in the world by a broad range of indicators obtained from mainly public indicators describing fertility, educational attainment, labour force participation, political empowerment and proportion of women among professional and technical workers.
}

ISSN: 07I 8-2724. (http://www.jotmi.org)

Journal of Technology Management \& Innovation (C) Universidad Alberto Hurtado, Facultad de Economía y Negocios 
(Lithuania, Slovakia), and lowest share in Germany, which invests heavily in R\&D in the business enterprise sector. Sweden interestingly stands out as a country investing heavily in industrial research but at the same time having higher than EU average proportion of women Ph.D.s in engineering, higher than EU average share of women professors in engineering, as well as women in industrial research.

\begin{tabular}{|c|c|c|c|c|c|}
\hline & $\begin{array}{l}\text { Proportion of } \\
\text { Women PhDs } \\
\text { in Engineering, } \\
\text { Manufacturing \& } \\
\text { Construction } \\
2006, \%\end{array}$ & $\begin{array}{l}\text { Proportion of } \\
\text { Women } \\
\text { Professors in } \\
\text { Engineering and } \\
\text { Technology 2007, } \\
\%\end{array}$ & $\begin{array}{l}\text { Proportion of } \\
\text { Women } \\
\text { Professors (grade } \\
\text { A) } 2007, \%\end{array}$ & $\begin{array}{l}\text { Proportion of } \\
\text { Women among } \\
\text { Reseachers in } \\
\text { Business } \\
\text { Enterprise Sector } \\
2006, \%\end{array}$ & $\begin{array}{l}\text { Proportion of } \\
\text { BES of } \\
\text { R\&D } \\
\text { expenditure } \\
2005, \%\end{array}$ \\
\hline EU-27 & 25 & 7.2 & 19 & 19 & $54.5 \%$ \\
\hline Austria & 21 & 5.2 & 14 & 14 & $45.8 \%$ \\
\hline Germany & 14 & 5.0 & 12 & 12 & $66.8 \%$ \\
\hline Greece & 25 & n.a. & II & 28 & $28.2 \%$ \\
\hline Finland & 24 & 6.4 & 23 & 18 & $69.3 \%$ \\
\hline France & 27 & 6.5 & 19 & 20 & $51.7 \%$ \\
\hline Lithuania & 40 & 4.5 & 14 & 35 & $20.8 \%$ \\
\hline Russia & n.a. & n.a. & $22(2004)$ & n.a. & n.a. \\
\hline Serbia & n.a. & $22(2006)$ & $28.4(2006)$ & n.a. & n.a \\
\hline Slovakia & 33 & 8.6 & 20 & 26 & $36.6 \%$ \\
\hline Spain & 25 & 8.1 & 19 & 28 & $48.0 \%$ \\
\hline Sweden & 29 & 8.3 & 18 & 25 & $65.0 \%$ \\
\hline UK & 22 & 7.0 & 17 & 19 & $44.2 \%$ \\
\hline Chile & n.a. & n.a. & n.a. & n.a. & n.a. \\
\hline
\end{tabular}

Table I. Proportion of women among Engineering Ph.D.s, Engineering Professors, and all Professors, among researchers in the Business Enterprise Sector, and the proportion of BES of total R\&D expenditure in the PROMETEA countries.

Sources: For EU countries: She Figures 2009; Key Figures 2007. Russia: Women and men in Russia 2004 and PROMETEA Report D8 and 9: State of the art, existing quantitative data, identification of gaps, and methodological overview; Serbia: Prometea Report D8 and 9 , Serbian data based on information from the Ministry of Education and Statistical Office of Republic of Serbia; Chile: PROMETEA Report D8 and 9.

\section{Methodology}

The gender dynamics of excellence in the technological and engineering research field was approached by gathering and analysing quantitative data on gate-keepers of excellence, i.e., decision-makers and evaluators granting and awarding excellence; those who were evaluated/defined as "excellent"; and potential gender monitoring of activities in these arenas, and contrasting this with qualitative data on perceptions and experiences of the few women who have advanced to the top in technological and engineering research. Data from each national setting was collected by the national PROMETEA research team (see footnote I), applying jointly developed guidelines.
Comparable data from PROMETEA countries and on different fields of technology was often difficult to obtain, sometimes due to differences in national research systems, or unavailability of or problems in access to gender data. Integrating German data into the study proved not to be possible in respect of all arenas of excellence. While there is a good deal of such data available in public sources (see, for example, http://www.gesis.org/cews, and Hinz, 2009) this could not be successfully accessed and collated into the appropriate form for strict comparative purposes for this particular study by the research partners in Germany.

The fuzzy boundaries between technological and engineering research towards other disciplines (for example, natural sciences, especially physics, and medicine), 
and the increasingly interdisciplinary and international research activities complicated data gathering and analysis even further. The increasingly important role of internationalization in technological research in different national settings was underlined as a result of the fieldwork, not only in terms of career mobility and funding but also affecting such key areas as publishing and conference practices.

Five arenas of excellence were originally examined: research funding, scientific publishing, conferences, prizes, and patents. Comprehensive gender data was not possible to obtain from all countries on all arenas, because of data gaps or simply research resource issues. This lack of certain data by gender and the difficulty of obtaining certain data are themselves of interest and constitute findings in themselves. Numerous data gaps were identified: data was often not readily available by gender and sometimes it was neither possible to obtain basic data at request so the PROMETEA national research teams could do the head counting themselves. In many cases it was not even possible to obtain information on gender distributions among the gate-keepers for national arenas of excellence.

Data on conferences was methodologically the most problematic and is not included in this article. In the following sections, key results concerning gender patterns in four arenas of excellence are be presented and discussed. More detailed data and references by country and a detailed methodological review is presented in Husu and Koskinen (2007). An analysis drawing on qualitative interview data on top women in technological and engineering research is also available in Husu and Koskinen (2010).

Exploring the first excellence arena, research funding, was complicated by the fact that the funding scene in technological research is rather diverse and complex in many of the participating countries (see also EC, 2009b). The focus in PROMETEA data gathering and analysis was on the national (public) funding systems.

The system by which public national research funding is allocated varies to some extent across the 13 countries involved as does research intensity and degree of competition for funding. These different "funding landscapes" obviously create different opportunity structures and career expectations for researchers in the national settings (see, for example, EC, 2009b). European and other international funding of technological research plays today a major role in funding of technological research, allocating large European funding to target technological fields such as nanotechnology and ICT. It was, however, not possible within the scope of this project to explore the gender dimensions of this international funding scene and its interplay with national funding scenes.

National PROMETEA teams were requested to collect data on major funding organizations for technological and engineering research in their country (both public and major private ones), obtain data on the gender composition of decision makers in these organisations (members of research councils, boards of major foundations), gender composition of referees and evaluators - if available; success rates by gender - if available; and information whether the organisation has a formal gender equality policy (for example, a gender equality plan). The data obtained on evaluators of research applications and success rates was fragmented (for more comprehensive recent data on 33 European countries, see EU, 2009b).

National data was to be collected on major national technology journals, their editorial staff by gender and gender division of articles published. International top journals in engineering and technology with highest impact factors in their field were identified using Thomson ISI Journal Citation Reports. The subfields used for engineering and for computer science were the ones used by the Thomson ISI system. A total of 18 top-ranked journals were included in the analysis, nine from both fields. The fieldwork of the PROMETEA national teams suggests that scientific publishing in the field of technology and engineering is shifting to focus increasingly on international arenas and publishing in English. Relatively small countries like Finland or Sweden with high technology research intensity, and even large European countries with a large research sector, such as France, do not have significant national scientific journals in the field, and the fieldwork for PROMETEA confirmed that researchers in these countries mostly publish and are expected to publish in international, English-language journals. However, the fieldwork indicated that in some, maybe more isolated participating countries, such as the Russian Federation, Serbia and Chile, national scientific technology journals are still published. 
Due to the relatively short timeframe of the project it was not possible to collect data on peer reviewers and article authors by gender as originally intended. Additionally, data was collected on patent applications and awards by gender and on most important national technology prizes, their selection committees and awardees by gender. National data on most important technology conferences, and gender composition of their organising committees, keynote speakers, and presenters was also planned to be included, but finally not realized, partly due to the fact that the initial data collection indicated that conference activities have become increasingly international.

From most countries, information on proportion of women as patent applicants or awarded patents was not available. In Russia, Serbia and Spain, the national PROMETEA teams in co-operation with the national patent authorities monitored the patent statistics from gender perspective, and in Finland, Sweden and Germany, results of some earlier studies on the issue were available.

A general problem in data collection was the frequent use of initials instead of first names in many of the organisations monitored, complicating the gender monitoring of gate-keepers. For example, even if the UK Engineering and Physical Sciences Research Council EPSRC had listed all of its $4000+$ grant evaluators by name on its website, which is a laudable practice to be recommended, it did not list the first name of them. (The gender distribution was, however, immediately sent to PROMETEA when requested). In the top international engineering journals we monitored, the name policy varied: some used initials only, some full first names, and some journals even used both systems. Interestingly, all but one top international computer science journals used full first names.

In some languages the last name is enough for gender monitoring purposes: for example, even if Russian national journals use initials and surname for authors, gender in Russian can be deducted from the form of the surname. A further complication for gender monitoring was caused by internationalization of research. It is sometimes difficult to tell the gender of a person even if her/his first name would be announced if the first name is in a language unfamiliar to the research team. In cases where only the initials of the first name were given, or when it was impossible to determine whether a full first name belonged to a man or woman, Google searches (including Google image search) were used. In most cases this made it possible to locate the person and define their gender on the basis of the person pronoun "she" or "he" was referred to on the website, or, somewhat less reliably, by their photographs published on the Web.

\section{Gender Patterns in Arenas of Excellence}

Given the small proportions of women in technological research field in general, an expected general pattern could be identified across the arenas of excellence explored: only few women either participate in awarding and decisionmaking on excellence in technological and engineering research as different gate-keepers, or are identified as "excellent". However, some arenas were identified in which gate-keeping positions appeared to be more open to women across countries.

The Research Funding Arena. In this arena, we were interested both in the gender composition of the gatekeepers of research funding but also in the gender composition of those who apply and receive funding (for a recent more comprehensive monitoring on European public research funding by gender, see EU, 2009b).

The gender composition of funding boards is important for various reasons. Those who decide on allocation of research funding are in an important gate-keeping position, able to influence and shape future research agendas. Participation as a gate-keeper can also enhance the gatekeepers' own research career, help him/her to integrate into powerful networks in the field and give privileged access to cutting-edge research.

Success in obtaining research funding is fundamental for advancing a career in research. Ability of and success in generating external research funding is often used as an indicator of excellence in career advancement and recruitment, especially in academia. This was also often underlined by many top women interviewed by PROMETEA.

Gate-keepers of major funding organisations: directors and boards. In general, only few women were found to have proceeded to a top gate-keeper position in the arenas of excellence explored. It is noteworthy that many of these top positions were found in the highest leadership or 
management positions of public national research funding organisations. These top positions include:

- in Austria, the Vice President of the Austrian Science Fund (central Austrian body to promote basic research);

- in Chile, the Chair of CONICYT (Chilean Research Council) and the Chair of the Science and Technology Fund Board;

- in Finland, the Chair of the selection committee of the world largest Technology Prize, the Millennium Award, and the previous Chair of the National Research Council for Natural Sciences and Technology;

- in France, the director of Agence National de Recherche;

- in Russia, the Assistant Manager of the Russian Fund for Theoretical Research;

- in the Slovak Republic, the Vice President of the Slovak Research and Development Agency;

- in Sweden, the Deputy Director General of the Swedish Research Council and the Deputy Director General of the Swedish Governmental Agency for Innovation Systems;

- in the UK, the Chair of the Engineering and Physical Sciences Research Council.

When it comes to boards of major national funding bodies, an equal representation of women and men was found only in the Finnish Research Council for Natural Science and Technology and in the equivalent Swedish Research Council. Both in Finland and Sweden a quota is applied to reach gender balance in public bodies, in Finland based on gender equality legislation (since 1995), in Sweden as a policy principle. In the French National Institution of Research, men direct seven out of its eight departments, and $21.4 \%$ of those in charge of evaluation of projects or coordinating research calls are women. In most Spanish funding organisations listed in our data there were several women among the boards, in the Spanish Foundation for Science and Technology four women out of 12 members. In the UK, women's presence in the decision-making body of the Engineering and Physical Sciences Research Council appeared to be improving: still in 2000-200 I the RC was chaired by a man and had no women members, but in 2003-2004, three out of 15 members were women and the organisation was also chaired by a female scientist, as already mentioned above. In the Russian Federation, of the nine listed major funding organisations, five had female members in their Council, typically one, while four out of the nine organisations had all-male Councils. Even less women were found in the Slovak Research and Development Agency and Technology Assistance Agency, with seven councils divided according to field of science; only one out of seven councils had a female member, among 13 men.

Women as evaluators and success rates by gender. In no country where gender data on evaluators was obtained did the proportion of women among evaluators exceed $30 \%$. In one country, Austria, there were no women among the evaluators of funding applications in the field of natural sciences and technology in the Austrian Science Funds FWF, the most important Austrian body funding basic research. The same organisation was neither able to make success rates by gender available.

The situation is somewhat different in Chile, where in 2007 $24.5 \%$ of the outside referees and $18.5 \%$ of internal referees of research funding proposals to the Science and Technology Development Fund (FONDECYT) were female. However, women had clearly lower success rate than men in engineering applications in FONDECYT funding in 2007 (women 28.6\%, men 43\%).

In Finland, gender balance among the evaluators is a policy aim for the National Research Council (the Academy of Finland). The proportion of evaluators of funding applications varies between 9 and $49 \%$ according to the type of funding and the research council. In 2007, 21\% of all evaluators were women, concerning general research project funding across all fields, but in the Research Council of Science and Technology, which was the focus of PROMETEA monitoring, only II\%. The Research Council reports that there is no gender difference in the success rate of women and men in research project funding in the period 200I-2006 in natural science and technology, and the average success rate for both men and women was $21 \%$.

In Serbia, $16 \%$ of the evaluators in the Ministry of Science and Environmental Protection research project funding were women in 2003-2007. Success rate by gender is not known but the proportion of women project leaders in the funded projects was 14\% overall in 2003-2005, and among project researchers women constituted a little less than a third. Highest proportion of women project leaders was 
found in biotechnology, where every fourth leader was female.

In the Swedish Research Council, in the research area science and technology $28 \%$ of the evaluators were women in 2005, highest proportion among the countries monitored. Gender balance among evaluators is also a policy aim. Women and men had nearly equal success rates in science and technology in 2005 for the research project grants (25.1\% women, $26 \%$ men were awarded). The average grant obtained by women was $87 \%$ of the grant obtained by men. However, in postdoctoral grant competition 2003-2005, women had a lower success rate (I7\%) than men (20\%).

In the UK, $12 \%$ of the evaluators of the EPSRC, Engineering and Physical Sciences Research Council, were women. Women's success rates in funding applications in 1998-200 I was nearly the same and sometimes even higher than men's, but the proportion of women among grant applicants was very low. In 200I, men's success rate was $36.2 \%$ and women's $37.5 \%$.

Publishing. Scientific publishing activity of a researcher is one key criterion in recruitment decisions and advancement in a research career, especially in academia. International peer reviewed journals are commonly considered as the most highly esteemed publishing arena.

Top international engineering journals were found to be produced mainly by male editorial staff. Engineering journals were compared to international top journals in computer science, were the situation was better. As Table 2 indicates, the proportion of women is low in both fields but there are still significant differences. No top engineering journal has a female editor-in-chief and these journals also have very few (8.7\%) women among other editorial staff. In the nine top computer science journals the situation is slightly better: there were two female editors-in-chief out of 14 totals, and 15\% of other editorial staff was female.

\begin{tabular}{|l|l|l|l|l|l|l|l|}
\hline Field & \multicolumn{2}{|l|}{$\begin{array}{l}\text { Engineering } \\
(9 \text { journals })\end{array}$} & $\begin{array}{l}\text { Computer science } \\
(9 \text { journals })\end{array}$ \\
\hline & $\mathrm{N}$ & women & $\%$ women & & $\mathrm{N}$ & women & $\%$ women \\
\hline $\begin{array}{l}\text { Editors-in-chief and } \\
\text { equivalent } \\
* *\end{array}$ & $\mathrm{II}$ & 0 & $0 \%$ & $\begin{array}{l}\text { Editors-in-chief and } \\
\text { equivalent** }\end{array}$ & 14 & 2 & $14.3 \%$ \\
\hline Other editorial staff*** & 253 & 22 & $8.7 \%$ & Other editorial staff*** & 473 & 71 & $15 \%$ \\
\hline
\end{tabular}

Table 2. Proportion of Women among Editors-in-Chief and other Editorial Staff at 18 Top-Ranked Engineering and Computer Science Journals*

Sources: Journals: Thomson ISI 2005 Journal Citation Reports. Editors and editorial staff: journals and individual journal websites, December 2006 - January 2007.

\footnotetext{
* Initially, Top 10 journals were identified by impact factor using the Thomson ISI ratings. The top journals in Engineering and Computer Science were determined by looking at the sub disciplines used by Thomson ISI Journal Citation system. It was impossible to obtain information of I journal in each group because of availability reasons: the journals were not online and were not subscribed by any Finnish technology libraries.

** Only Editors-in-Chief, some journals have more than one.

*** Includes editorial boards, editorial committees, associate editors, editorial assistants etc.

The figures are from 18 journals, 9 from engineering field and 9 from the field of computer science. The use of initials is very common and not all names could be identified as either male or female.
}

ISSN: 07I 8-2724. (http://www.jotmi.org)

Journal of Technology Management \& Innovation (C) Universidad Alberto Hurtado, Facultad de Economía y Negocios 
The situation in national journals, in the few countries covered where such are published, is much the same. In Chile, some national journals had a female editor. In the Russian Federation, engineering publishing scene appears to be lively. The Russian PROMETEA team mapped extensively gender data both on international journals published in the Russian Federation, some of which are published in Russian and English, some only in Russian, and on national journals for 2005. Some of the national journals have more purely scientific orientation, some are more practically oriented, and some a mixture of these (for detailed tables, see Husu and Koskinen 2007). In the Russian technology journals in 2005 some female editorsin-chief and deputy editors-in-chief were identified, especially in the field of transport (journal Transit), and also in some journals from the field of energy. The journal World Energy Science, which is practically oriented, had a female editor-in-chief in 2005.

Prizes and awards. Scientific awards and prizes are traditional ways to indicate excellence. Nobel Prize is not awarded in Technology and Engineering field but there are some other, relatively newly established significant international awards in the area. The number of women among awardees of Technology and Engineering prizes and awards is, as expected, very small. 12 PROMETEA country teams provided data on the subject. The data varies a great deal both in quality and quantity but, as was expected, men dominate this field both as gate-keepers and awardees. Transparency of the nomination procedures also varies. In best cases, the nomination criteria and past and present nomination committees are listed member by member with full names in the website of the awarding organisation, together with lists of awardees and their short CVs. This is the case for most international technology prizes. On the other hand, in many national cases the information on the composition of committees is not available and thus gender monitoring is often impossible. According to this data, the best national situations can be found in Serbia and in Spain where there are several women in the committees awarding prizes. Special prizes and awards for women in technology and engineering were not reported except from Austria, Chile, Finland and the UK.

Altogether six major international prizes and awards were chosen for more detailed analysis. These were The Millennium Technology Prize, the three prizes awarded by the US National Academy of Engineering (Draper Prize, Russ
Prize and Gordon Prize) and the two Japan-based international technology prizes; Japan Prize and Kyoto Prize. ${ }^{6}$ These prizes were selected on the basis of information gathered from several stakeholders in the field. Data was collected up to year 2006.

Based on the data gathered about these six prizes, the number of women that have been awarded major international prizes in technology is extremely small: only 4 women compared to 136 men. In fact, only two women have been awarded major international prizes thus far, if one counts out the two women who have been awarded a major prize, given to US-based or US-linked persons only, namely the Gordon prize, awarded by the US National Academy of Engineering. Analysis of prizes and awards shows that no female engineering and technology researcher had been awarded a major international technology prize thus far. The very few women who had been awarded prizes in this category were mostly from biological sciences.

Gate-keepers of the large international prizes are nearly exclusively male. In the selection committees of the international Japan-based prizes there were no women, but in selection committees for all the other international prizes there were a few. Furthermore, the Millennium Prize Foundation, based in Finland, awarding world's largest technology prize of one Million Euros appointed in 2007 the first woman to chair its Selection committee, and the three US based "Nobel Prizes of Engineering" all have 2-3 women in their Selection committees.

When it comes to the national prizes, in Chile, only one woman has ever won a significant science and technology prize; in France, no women have received the two most prestigious French prizes; the most prestigious Russian prizes have not been given to any women during recent years. In Spain, the prestigious Prince Asturias Foundation Award for Science and Technology, sometimes considered as the Spanish equivalent to the Nobel Prize, has thus far been given only once to a female scientist (to the prima-

\footnotetext{
${ }^{6}$ Millennium Technology Prize: http://www.millenniumprize.fi/; Draper Prize; http://www.draperprize.org/; Russ Prize: http://www.nae.edu/Awards/RussPrize8693.aspx; Gordon Prize: http://www.nae.edu/Awards/GordonPrize8695.aspx; Japan Prize: http://www.japanprize.jp/en/prize.html; Kyoto Prize: http://www.inamori-f.or.jp/e kp out out.html.
} 
tologist Jane Goodall in 2003). In Serbia, one out of four prestigious Tesla prize winners was a woman in 2005 and 2006. A comprehensive analysis by the Swedish PROMETEA team included eight Swedish national technology prizes and awards and their all-time award winners until 2006. Five of these different awards had until then never been given to any woman, and of 590 all-time award winners only $3 \%$ have been women. In Finland, a few women have only relatively recently received the national most important technology prize.

Patents. Patent data was not easily available by gender as mentioned earlier. The proportion of women among patent awardees was highest in Spain (11\% on average in 200I-2005) and in Serbia (1I \% on average in 1996-2006) and lowest in Russia, 4\% in 2005, whereas in Germany $9 \%$ of patents were awarded to women in 2003, and in Finland, $6 \%$ in the period of $200 \mathrm{I}-2005$.

\section{Gender Monitoring}

Gender monitoring in its simplest forms means head counting to produce basic gender statistics. It can also mean sophisticated analysis of gender dynamics of the monitored issue or field, the results of which are consequently used in organisational development and in planning for gender equality interventions. To promote gender equality in an organisation or area without even basic gender statistics available is simply impossible. Gender issues appeared to be not much of a concern on most arenas of excellence in engineering and technological research in most countries studied. The PROMETEA research effort revealed large gaps in data availability by gender in most countries and organisations studied. Systematic gender monitoring in the arenas of excellence explored appears to be rare with a few exceptions, such as the Swedish and Finnish Research Councils. No national patent authority was found to perform gender monitoring on patent applicants and awards on a regular basis.

However, gender monitoring was lacking on some arenas even in countries characterized by small societal gender gap, where gender statistics and gender monitoring are generally well advanced and performed nearly routinely in many areas of society. Example of this kind of finding is that in Sweden information on the composition of committees deciding on recipients of major national awards and prizes in engineering and technology was not possible to obtain. It was also noteworthy that the two large technology research funding organisations from the Nordic countries, both public sector organisations, VINNOVA from Sweden and TEKES from Finland, did not at the time PROMETEA data was gathered regularly collect gender statistics on their funding. ${ }^{7}$

On the other hand, it was relatively easy for the PROMETEA team to gender monitor gate-keepers and selection process for and recipients of international technology prizes. This information was readily available on the websites of the prize-giving organisations, even if the research team had to do the head counting. Many stakeholder organisations also have informative websites, and many of them responded swiftly to the requests for data from PROMETEA research team. In general, research of this kind has been greatly facilitated during the recent years due to the fact that many stakeholder organisations have started to publish more and more information on their organisation, activities and policies online. However, very few stakeholder organisations in Europe use the opportunity to openly and pro-actively provide this kind of information by gender.

\section{Analysis of Findings}

Technological and engineering research is heavily maledominated and, as might be expected, the arenas of excellence in technological research are even more so. The heaviest male dominance was identified in international arenas of excellence, such as in editorial positions of top international engineering journals, and among decision-makers and recipients of the most significant international technology prizes and awards, where hardly any women were involved. However, women were slightly better represented in computer science top journal editorial staff, and there were two female editorsin-chief in top computer science journals.

In the national settings explored, male dominance is also obvious, but the picture becomes more varied, and clear patterns or clusters of countries were rather difficult to identify. One clear pattern was that top research management and leadership positions in public funding

\footnotetext{
${ }^{7}$ VINNOVA has, however, recently integrated increasingly gender perspectives in its activities, see, for example, http://www.vinnova.se/en/Activities/Needs-Driven-GenderResearch-for-Innovation/, referred April 9, 2010, and a google search on VINNOVA website in 2010 gives 139 hits (referred May 13, 2010).
}

ISSN: 07I 8-2724. (http://www.jotmi.org)

Journal of Technology Management \& Innovation (C) Universidad Alberto Hurtado, Facultad de Economía y Negocios 
organisations appear to be more open to women (compared to the situation in other arenas of excellence), albeit in very different national settings. These were identified especially in countries with high overall societal gender equality and high research intensity (Finland, Sweden), in Eastern European countries with relatively large gender gap and low research intensity (Russian Federation, Slovak Republic), in Western European countries with largest research sectors (France, UK), and even in Austria and Chile, countries with relatively low research intensity and relatively high societal gender inequality. One can ask is this an indication of that there is less resistance against women's entry and career advancement in public research funding organisations than in top research in universities, industry and research institutions. The issue deserves further more detailed studies.

Among research funding decision-makers equal representation of women and men was found only in countries with very small societal gender gap, and in which gender balance in public decision-making is a policy principle guaranteed by law (Finland, gender equality legislation) or is a through-going policy principle (Sweden). Gender equality as a policy principle is also paid attention in the UK, which is evidenced in the improving gender balance of the Engineering and Physical Sciences Research Council, and more recently in Spain. It is noteworthy that in Finland, Sweden and the UK, the Research Councils also monitor success rates of applicants by gender and furthermore were also able to provide time series on this. In France, the Russian Federation and Slovak Republic male domination among funding gate-keepers was clearly stronger and there was little indication of attention to gender equality in research policy (see also EC, 2009). Among the evaluators of research proposals the share of women did not exceed a third in any of the PROMETEA countries, not even in Finland and Sweden which both have policy targets on gender balance among evaluators. No large differences in success rates in funding applications of women and men were reported in favour of men, except from Chile where men had clearly higher success rate, but it should be pointed out that success rate data was not obtained from many other countries with low research intensity and large societal inequality.

Importantly, as publishing in engineering and technology research has become increasingly international, the national publishing arenas have either vanished or their importance has diminished. In countries where national journals still are published, such as the Russia Federation and Chile, some women editors-in-chief could be identified.

Major international technology and engineering prizes have been given almost exclusively to male scientists, the few women having received these prizes coming mostly not from engineering and technology but from other fields such as biological sciences. Some of these international prizes have no women in the selection committees but some recent positive development could be identified, such as that the selection committee of the Millennium Prize, world's largest technology prize of one million Euros, appointed in 2007 the first woman to chair its selection committee. It is noteworthy that this price is based in Finland, a country with among the smallest gender gaps globally and with advanced gender equality policies.

Indeed, among winners of most important national prizes a large number of prizes could be identified which had never been awarded to women. Surprisingly, this was the case also in Sweden, a country with a small societal gender gap and high gender awareness. By 2006, five of the eight Swedish national technology prizes and awards had never been given to a woman, and overall women had received only $3 \%$ of 590 Swedish awards given until 2006. This seems an especially male-dominated area, where both the composition of judging panels may be strongly homosocial and the process of judging may be heavily embedded with gendered assumptions what counts as exceptional or outstanding.

The general male domination of arenas of excellence in technology and engineering could be said to be, or represent the product of, a triple dominance. First, there is the male dominance of most of the fields of technology and engineering, both numerically and in terms of leadership positions. Second, this is reinforced by further processes of homosociality, inclusion and exclusion in both the control, gate-keeping and decision-making on excellence, and the award of excellence itself. And third, these gendered processes of gendered excellence are becoming increasingly international rather than national, with their own patterns of international networks, organisations and institutions. These last forms of the organising of excellence could be said to be social gendered relations 
between local, national, disciplinary and professional organising of excellence, themselves gendered.

\section{Conclusions and Policy Implications}

The arenas of excellence in engineering and technology are extremely male-dominated both when it comes to their gatekeepers and to those who are defined as "excellent". In most arenas of excellence, gender is not considered as an issue in most of the countries studied - gender equality is not on the agenda, active policies and measures in order to get more women involved are lacking, and gender balance is not monitored. Only the high management and leadership positions in national research funding organisations seem to be (slightly) more open to women, and in very different national settings.

A first policy recommendation based on the findings repeats earlier recommendations by the European Commission on improving scientific excellence by promoting gender awareness and fairness (EC, 2005b): a need to increase transparency and accountability of all stakeholder organisations on arenas of excellence from $a$ gender perspective. Practically all stakeholder organisations should significantly improve their gender monitoring: this should be a concern for research funding bodies, journals and publishers, conference organisers, award and prize committees and patent authorities. Gender data on key actors in these stakeholder organisations should not only be collected, monitored and available at request, but also made pro-actively and publicly accessible on a regular basis, for example, using websites of these organisations where other information of similar kind is regularly made accessible. This would benefit both policy development and research, as well as public accountability. Only a few stakeholders studied by PROMETEA meet high standards in this respect and can act as good practice examples, such as the Swedish Research Council, producing and making publicly available detailed gender monitoring data on most of its activities on a regular basis, and using the data to inform and reform its activities. Most research stakeholders currently monitor and are demanded to monitor their activities in various ways, either by political decision-makers or different constituencies including scientific and professional societies, and there is no reason why gender monitoring should not be integrated into these kinds of quality assurance activities.
A further policy recommendation concerns the composition of different gate-keeper bodies of technology and engineering stakeholder organisations. All-male committees defining and deciding on excellence should not be accepted as legitimate, because even if the field of engineering and technology is heavily male-dominated, there are women involved at all levels and most areas. In a few countries, such as Finland and Sweden, legislation and/or public policy stipulate gender balance in public boards such as public research councils. In most countries this is not the case, and thus active efforts of the stakeholder organisations themselves are needed to increase the proportion of women among gate-keepers through targets, quotas, active searches and reviewing/revisiting appointment criteria and definition of competence. It is a fact that the proportion of women among full professors in technology and engineering is only $7.2 \%$ in the EU-27, which is often used as an argument to defend the scarcity of women among gate-keepers. One solution could be broadening the search: there are plenty of competent engineering and technology research experts, women and men, also outside the professoriate, in industry, business and public sector. More women could and should be engaged in key gate-keeping activities which are shaping the future of technological and engineering research and society.

The PROMETEA research effort on exploring the gendering of arenas of excellence should be seen as an exploratory mapping exercise, which hopefully will inspire further, more detailed research. The picture thus created on the gendering of excellence in technological research is far from comprehensive but rather patchy, for several reasons. Further studies are needed to perform systematic analysis of the dynamics of gendering of excellence in the five arenas under scrutiny, also comparing different subfields of technology, which might have slightly varied gender dynamics. For example, many top women in technology interviewed by PROMETEA indicated that they assessed women to have better opportunities in relatively new fields of technology, such as biotechnology.

\section{References}

CARTER, R., Kirkup, G (1990). Women in Engineering: A Good Place to Be? Macmillan, Basingstoke.

CEWS, Center of Excellence Women in Science, Germany, http://www.gesis.org/cews. 
DANOWITZ SAGARIA, M. (ed.) (2007). Women, Universities, and Change. Palgrave, New York.

DFG - German Research Foundation (2008). Excellence Initiative at a Glance. DFG, Bonn.

EC (European Commission) (2004). Gender and Excellence in the Making. Office for the Official Publications of the European Commission, Luxembourg.

EC (European Commission) (2005a). Key Figures 2005. Towards a European Research Area. Science, Technology and Innovation. Office for Official Publications of the European Communities, Luxembourg.

EC (European Commission) (2005b). Women and Science. Excellence and Innovation - Gender Equality in Science. Office for Official Publications of the European Communities, Luxembourg.

EC (European Commission) (2007). She Figures 2006. Women and Science Statistics and Indicators. Office for Official Publications of the European Communities, Luxembourg.

EC (European Commission) (2009a). She Figures 2009. Women and Science Statistics and Indicators. Office for Official Publications of the European Communities, Luxembourg.

EC (European Commission) (2009b). The Gender Challenge in Research Funding. Office for Official Publications of the European Communities, Luxembourg.

ETAN European Technology Assessment Network (2000). Science Policies in the European Union. Promoting Excellence through Mainstreaming Gender Equality. A Report of the ETAN network of Women in Science. European Commission, Research Directorate General, Brussels.

FAULKNER, W. (2000). The Power and the Pleasure? A Research Agenda for Making Gender Stick to Engineers. Science, Technology and Human Values, 25(I), 87-I 19.

GODFROY-GENIN, A. (ed.) (2010). Women in Engineering and Technology Research. Proceedings of the PROMETEA Conference, Paris, October 26-27, 2007. Lit Verlag, Paris.
HAUSMANN, R., Tyson, L.D., Zahidi, S. (2009). The Global Gender Gap Report 2009. World Economic Forum, Geneva.

HINZ, T. (2009). The gender challenge in research funding. Assessing the European national scenes. Germany. http://ec.europa.eu/research/science-society/document libra/pdf 06/germany-research-funding en.pdf (Accessed May I, 2010).

HUSU, L., Koskinen, P. (2007). Report on gendering of excellence in technological and engineering research. PROMETEA - Empowering Women Engineers in Industrial and Academic Research. Periodic Progress Report to the European Commission. University of Helsinki, Helsinki.

HUSU, L., Koskinen, P. (2010). What does it take to get to the top? Women at the top of technological research". In: Godfroy-Genin, A. (ed.), Women in Engineering and Technology Research. Proceedings of the PROMETEA Conference, Paris, October 26-27, 2007. Lit Verlag, Paris. PP. 303-326.

MCILWEE, J.S., Robinson, J.G. (1992). Women in Engineering: Gender, Power, and Workplace Culture. SUNY Press, New York.

MELLSTROM, U. (1995). Engineering lives: Technology, time and space in a male-centred world. Department of Technology and Social Change, Linköping, Sweden.

SCHIEBINGER, L. (1999). Has feminism changed science? Harvard University Press, Cambridge, London,

SJOBERG, S. (2000). Science and scientists: the SAS study. Cross-cultural evidence and perspectives on pupils interests, experiences and perceptions. University of Oslo: Department of Teacher Education and School Development. Acta Didactica I, 2000. 